\title{
Comment on "Counting the World's Poor," by Angus Deaton
}

\author{
Martin Ravallion
}

There is almost never just one way to measure an economic variable, and poverty is no exception. Judgments are required about the best method-given the data available - at virtually every step, starting with the design and processing of the underlying household survey data. The judgments made should be explicit and subjected to independent review.

In that spirit, Deaton (this issue) provides a usefully critical discussion of the current methods used by the World Bank for measuring poverty. This is welcome and timely. It is welcome in part because it is by Angus Deaton, who for 20 years has been a leading scholar on the theory and methods of welfare measurement using household-level data. And it is timely because of recent concerns about whether our current measurement tools fully reflect how the living conditions of the world's poor are changing.

I will not address all the points raised by Deaton — avoiding those on which I think there is broad agreement that the World Bank's current methods could be improved. These include the way that (invariably troublesome) income surveys are handled, the scope for better use of subjective-qualitative welfare data, and the need to better acknowledge the limitations of welfare metrics based solely on consumption of market goods.

This leaves two main issues that are very important for global poverty measurements - namely, how currency conversions are done and whether the poverty measures should be anchored to the national accounts. On both counts, Deaton makes recommendations for changing current methods. Before considering his recommendations, I will briefly describe how the World Bank measures poverty.

\section{How Does the World Bank Measure Poverty?}

The World Bank's poverty measures based on the \$1/day line began with the 1990 World Development Report (World Bank 1990). That report provided estimates for developing countries as a whole and by region for 1985, based on 22 household 
surveys, one for each of 22 countries, and model-based extrapolations for other countries (Ravallion and others 1991). Since then, the data set has expanded to include nearly 300 surveys spanning about 90 countries, with an attempt to provide consistent comparisons over time. The latest version of the main summary table by region gives estimates for 1987, 1990, 1993, 1996, and 1998 (Chen and Ravallion 2000).

The essential features of the current methodology can be summarized as follows. ${ }^{1}$ An international poverty line is chosen as being typical of prevailing poverty lines used in a sample of low-income countries (World Bank 1990; Ravallion and others 1991). ${ }^{2}$ The international poverty line is converted to local currency using the latest available purchasing power parity (PPP) exchange rates for consumption. The best available consumer price indexes are then used to convert the international poverty line in local currency to prices prevailing at the time of the surveys. These poverty lines are applied to distributions of consumption per person (or income if consumption is not available) constructed from nationally representative household surveys. Adjustments to the data are often required for consistency, such as ensuring that population weights are used to obtain an unbiased estimate of the individual distribution of household consumption per person. Calculations are done from the primary data (either micro data or appropriate tabulations).

These aggregate (global or regional) poverty measures based on international poverty lines should not be confused with measures based on national or subnational lines. The vast bulk of the World Bank's poverty monitoring effort does not use PPP exchange rates at all. At the country level, poverty monitoring is based on poverty lines considered appropriate in each country, which are updated over time. The PPP rates are required only for forming regional or global aggregates, for which the judgment is made that any two people with the same command over commodities should be treated the same way no matter where they live. Thus the aggregates ignore individual country poverty lines. The measures based on international poverty lines are presented side by side with national poverty lines in World Development Indicators (World Bank 2000) and the Bank's Global Poverty Monitoring Web site, which gives the individual country estimates over time for a range of poverty lines and measures (www.worldbank.org/research/povmonitor/).

\section{Currency Conversions for International Poverty Lines}

The practice of using PPP exchange rates in forming global poverty aggregates goes back to the first World Development Report on poverty (World Bank 1980). This method is clearly preferable to using official exchange rates, but it has long been recognized that using PPP exchange rates is not ideal. Since the 1990 World Development Report, the consumption PPP rates have been used, rather than PPPs for aggregate 
output. This avoids some of the problems noted by Deaton. However, PPP exchange rates were not designed for the purpose of making internationally comparable poverty lines, but rather for making comparisons of average national income and consumption. The problem is coming up with something better.

Deaton is concerned about the impact of revisions to the source data on PPP rates for the global poverty measures. The PPP exchange rates have been updated over time, with the latest using the 1993 price data from the UN International Comparisons Project, entailing considerable improvement in the coverage and quality of the underlying data on prices. The underlying distributional data have also been updated regularly. With new data, all preceding calculations are also corrected back in time to ensure internal consistency.

The World Bank always uses the most recent data available for each update (three times a year). That includes all the new survey data (including going back in time) as well as new PPPs. Deaton is right that this produces some sizable revisions. For example, in the latest version of the main regional tabulation (Chen and Ravallion 2000), the share of world poverty attributed to Sub-Saharan Africa has risen relative to previous versions, due partly to revisions in the PPP exchange rates for this region. These revisions have also reduced the global rate of poverty reduction because poverty has increased in Sub-Saharan Africa. However, there has not been a downward revision of the Bank's overall \$1/day head count of poverty for the most recent common year between the latest estimates and the previous estimates, namely, 1993. For that year, the new estimate is 1.31 billion people living below $\$ 1 /$ day (Chen and Ravallion 2000); previously, we estimated 1.30 billion (Ravallion and Chen 1997). However, the regional composition of poverty has changed, with a higher proportion of the poor in Sub-Saharan Africa (reflecting the new data on price levels as well as new survey data for relatively poorer countries).

It is hard to argue that we should ignore new data on either the distributions or the PPP exchange rates. This is one worry about Deaton's proposal of not updating PPPs; it could create persistent drift from accepted international comparisons. I am also worried about the judgments for which Deaton's proposal calls, in making sure that the PPP lines are "plausible." The problem is knowing what is plausible. The researcher might be unduly persuaded by dubious priors - raising concerns about the transparency and objectivity of the measures.

\section{Disparities between Survey Data and the National Accounts}

There are two main sources of data on people's average command over commodities. One is the level of private consumption expenditure per capita from the national accounts (NAS). The other is average household expenditure on consumption obtained from a national sample survey of households - typically the same survey used 
to measure poverty. Unlike the NAs, surveys also tell us about the distribution of consumption and/or income.

There are differences between the two data sources in terms of coverage, definitions, and methods. For example, as it is measured in practice in most developing countries, "private consumption" in the NAs includes spending by nonprofit enterprises (charities, nongovernmental organizations, and political parties) as well as households. In some countries (such as India), the survey-based consumption measure does not include imputed rents for owner-occupied housing. There are also measurement errors in both data sources. Survey measures entail both sampling and nonsampling errors; underreporting of income and consumption is thought to be a common problem in surveys. There are comparability problems between surveys (between countries and over time), such as due to differences in questionnaire design. NAS consumption is also prone to error, given that it is not directly measured in the NAS but is often inferred residually after accounting for more directly measured channels of output absorption at the commodity level.

It is not surprising that the two data sources do not agree in general. The discrepancy with the NAS is significantly greater for income surveys than consumption surveys (Ravallion 2001). This echoes the long-standing concerns (on both theoretical and practical grounds) about using income surveys for measuring poverty to which Deaton refers. Consumption surveys give numbers that are about as close as one might expect to private consumption in the NAs, on average. But here, too, there are some sizable deviations from the average. For example, for India aggregate consumption in the National Sample Survey (NSS) is about 60-70 percent of consumption in the Nas during the 1990s (depending on the method used to measure consumption in the NAS). Across countries in the 1990s, growth rates in mean consumption from surveys have tended to be lower than those from the NAs. They are only slightly lower as a rule, but more markedly so in some cases, including India and much of Eastern Europe and Central Asia (where there is remarkably little correlation between data from the two sources; see Ravallion 2001).

The discrepancies between consumption estimates from these two sources for India have fuelled a debate about whether the Nss is capturing the full gains to the poor from the country's postreform economic growth in the 1990s. It seems that, in some kind of contagion, these concerns have spilled over to the rest of the developing world. One observer even claimed that the World Bank measured poverty the way it didbased on surveys for measuring the levels of household consumption and incomebecause it was in the institution's interests to deliberately understate the extent to which economic growth was reducing poverty in the world (Bhalla 2000). As Deaton notes, although it is a current debate in India, this is not a new debate there or elsewhere; for example, the same issue has been raised before in the contexts of concerns about underreporting of income in the (many) income surveys used for poverty measurement in Latin America. The recent perception in some quarters that something 
is seriously wrong in the existing poverty monitoring efforts makes Deaton's assessment even more welcome.

In some respects, the fact that this debate has resurfaced in India might be surprising. India had not previously been seen as a country with problematic survey data. Indeed, India's poverty monitoring based on the Nss has been widely seen as a model for other countries (although this perception has faded somewhat over time, as survey methods have advanced elsewhere). We do not have any new information about the survey's design and implementation to make us suspect that something has gone wrong with the Nss in the 1990s, at least prior to the latest (55th) round for 19992000. And expectations for rapid poverty reduction, postreform, may well have been optimistic. There are reasons why the type of growth seen in the 1990s, given initial conditions in much of the country, would not yet be evident as greatly reduced poverty (Ravallion 2000b).

It should also be noted that the extent of divergence between the two data sources depends in part on measurement choices. Applying more consistent definitions of "consumption" between the two sources can go some way toward reducing the gap; see, for example, Slesnick (1998) on the United States. Two examples from India illustrate the dependence on methodology.

The first example concerns the methods used by the NAs. The appearance of sizable divergence between Nss and NAS consumption aggregates for India in the 1990s can be deceptive unless one takes account of the changes in methods used by the NAs. When the central statistics office changed its methods to accord more closely with new international standards set in 1993, there was a sizable upward revision in the NAS consumption estimates in the 1990s. Some observers have calculated the ratio of aggregate consumption from India's NSs to that in the NAS ignoring the switch in NAS methods; this gives a deceptively large fall in the ratio in the 1990s. Comparing estimates using the same methods, Sen (2000) finds little sign of a decrease in the ratio of Nss consumption to NAS consumption during the 1990s, although there are signs of a longer-term trend decline in this ratio going back to the 1970s. The bulk of the decline precedes the 1990s and clearly has nothing to do with the reforms.

The second example reinforces Deaton's comments on how much survey design can matter. There were important changes in the consumption questions in the 1999-2000 (55th) round of the Nss, breaking from methods used consistently since the 1950s. The 55th round shows a sizable reduction in poverty in India. However, we do not know how much of this is real and how much is due to the changes in survey design. By one assessment, the conclusion that poverty fell is not robust to attempts to deal with the likely comparability problems raised by the 55 th round (Sen 2000). Other assessments suggest that poverty has indeed fallen, although not nearly as much as the 55th round implies. Nor has it been demonstrated that the changes made to the design of the Nss in the 55th round will give more precise consumption 
estimates; that is not obvious on a priori grounds. Further experiments on alternative survey methods are needed, as well as a plan for data transition to allow consistent comparisons over time.

\section{Implications for Poverty Measurement}

Discrepancies between the surveys and the national accounts have implications for poverty measurement that depend critically on the reasons for the divergence. Deaton is right that further research on this issue is called for. One interpretation assumes that any discrepancy is entirely due to underestimation of mean consumption in the surveys, but that the surveys nonetheless get relative consumption and hence inequality right. If one accepts that interpretation, then the solution is simple: just replace the mean from the surveys with the consumption mean from the NAs and recalculate the poverty measures (as in, for example, Bhalla 2000). A more sophisticated version of the same basic method takes the mean consumption or income components in the surveys and scales them up to accord with the NAs. Although agreeing that the surveys probably miss some of the consumption gains, an alternative interpretation says that the problem has much more to do with consumption by the nonpoor, and that the surveys more likely underestimate the rate of increase in inequality.

It has not been established, and is quite unlikely from what we know, that the discrepancy between the two data sources is entirely due to underestimation of consumption levels in the surveys. But even if that were the sole source of the discrepancy, it is hard to believe that the surveys would be getting the mean wrong but inequality right. Our limited knowledge of the problems of underreporting and noncompliance in consumption and income surveys does not suggest that the problem is likely to be distribution neutral. In consumption surveys, the bulk of the problem is thought to be for the nonpoor. (In income surveys, there is possibly also underestimation of annual income of the rural poor using survey questions based on subannual income recall, given seasonality.) If the problem arises from underestimation of consumption by the nonpoor, then the correct mean for measuring poverty is the mean of the survey distribution, although this underestimates the true mean (Ravallion 2000a). In other words, for measuring poverty, there is an error in the mean that offsets the error in estimating the distribution around the mean. However, it is unlikely that none of the discrepancy arises from underestimation of consumption at the poverty line. At least some of the error is probably passed onto the poverty measure at any given poverty line.

What can be done? If one accepts that some of the discrepancy is due to underestimation of consumption at the poverty line, then in theory there must exist a scaling factor applied to the survey mean that will give the right poverty measure at the given (but also wrong) distribution. Although we can postulate its existence in theory, 
we have no basis for setting this scaling factor. Nor is it plausible that the error is a strictly decreasing function of the scaling factor; there will be scaling factors greater than unity that give less accurate measures than using no scaling at all.

Deaton recommends taking a weighted average of the two measures of consumption, one from the survey and one from the NAs. (Then the scaling factor is a linear function of the ratio of NAS consumption to survey mean consumption.) It is not clear why this would be better than no adjustment. Combining the two measures of average consumption may well give a better estimate of the mean. But that is not the statistic in which we are interested. The problem is how to set that weight when the aim is to reduce the error in the poverty measure. As yet, there is no obviously defensible solution in sight, and there is no basis for presuming that anyone's guess will give a better measure than using no adjustment at all.

There is also a question of whether anchoring the poverty measures to the national accounts would foster better poverty monitoring in the future. The World Bank's practices in poverty measurement reflect a judgment that the household surveys should ideally stand as a data source largely independent from the NAs. In this view, the surveys should be the main testing ground for claims made about the impacts of policy or economic changes on the poor.

Yes, there are problems galore in the existing surveys. But, as Deaton notes, the World Bank also has an important role to play in supporting efforts at the country level to improve and standardize the surveys, such as through the ongoing Living Standards Measurement Study and related support in promoting household survey capabilities in developing countries.

\section{Notes}

Martin Ravallion is research manager with the Development Research Group at the World Bank.

1. The methods are described in more detail in Ravallion and others (1991); Chen and others (1994); Ravallion and Chen (1997); and Chen and Ravallion (2000).

2 . The countries include India, which had been the country on which international poverty comparisons were based for the first World Development Report on poverty, namely, World Bank (1980). The $\$ 1 /$ day line is close to the mean for a larger set of low-income countries. The line is updated with revisions to the purchasing power parity exchange rates (as discussed in Chen and Ravallion 2000).

\section{References}

Bhalla, Surjit. 2000. "Trends in World Poverty: Research and Ideology." Available online at www.oxusresearch.com.

Chen, Shaohua, Guarav Datt, and Martin Ravallion. 1994. "Is Poverty Increasing or Decreasing in the Developing World?” Review of Income and Wealth 40:359-76. 
Chen, Shaohua, and Martin Ravallion. 2000. "How Did the World's Poorest Fare in the 1990s?” Policy Research Working Paper 2409, World Bank, Washington, D.C.

Ravallion, Martin. 2000a. "Should Poverty Measures Be Anchored to the National Accounts?" Economic and Political Weekly 34(3):245-52.

_. 2000b. "What Is Needed for a More Pro-poor Growth Process in India?" Economic and Political Weekly 35:1089-93.

—. 2001. "Measuring Aggregate Welfare in Developing Countries: How Well Do National Accounts and Surveys Agree?” Policy Research Working Paper 2665, World Bank, Washington, D.C. Available online at http://econ.worldbank.org.

Ravallion, Martin, and Shaohua Chen. 1997. "What Can New Survey Data Tell Us about Recent Changes in Distribution and Poverty?” World Bank Economic Review 11(2):357-82.

Ravallion, Martin, Gaurav Datt, and Dominique van de Walle. 1991."Quantifying Absolute Poverty in the Developing World.” Review of Income and Wealth 37:345-61.

Sen, Abhijit. 2000. "Estimates of Consumer Expenditure and Its Distribution: Statistical Priorities after the NSS 55th Round.” Economic and Political Weekly 35(51):4499-518.

Slesnick, Daniel. 1998. "Are Our Data Relevant to the Theory? The Case of Aggregate Consumption." Journal of Business and Economic Statistics 16(1):52-61.

World Bank. 1980. World Development Report: Poverty and Human Development. New York: Oxford University Press.

—. 1990. World Development Report: Poverty. New York: Oxford University Press.

—. 2000. World Development Indicators. Washington, D.C.: World Bank. 